\title{
Telemonitorering gir nye roller for både pasient og sjukepleiar
}

\author{
Stadig fleire eldre får kardiovaskulære sjukdommar. Skal vi klare å ta hand om desse pasientane og \\ administrere system for telemonitorering, må vi vidareutvikle den tradisjonelle sjukepleiarrolla.
}

\section{FORFATTERE}

\section{Ewy Katrin Førde Moen}

Spesialsjukepleiar i geriatrisk og kardiologisk sjukepleie

Førde sentralsjukehus, Medisinsk poliklinikk

\section{Dag Fadnes}

Overlege, spesialist i indremedisin og hjertesykdommer, og universitetslektor Førde sentralsjukehus og Universitetet i Bergen

\section{Tone Merete Norekvål}

Fag- og forskningssykepleier og professor

Haukeland universitetssjukehus, Universitetet i Bergen og Høgskulen på Vestlandet

\section{NøKKELORD}

Geriatri, Demens, Kardiologisk sykepleier

\section{HOVEDBUDSKAP}

Det blir fleire eldre menneske med kardiovaskulære sjukdommar, og dei aldersrelaterte kompleksitetane blir meir omfattande. Derfor er det behov for å omdefinere behandlingsstrategiane, måla og dei ønskte resultata for denne gruppa. Ved hjelp av telemonitorering (TM), som trådlaust sender informasjon frå ein pacemaker (PM) via ein server til helsepersonell på sjukehuset, kan vi tilpasse kontrollrutinane for pasientar med PM. Skal vi klare å ta hand om pasientane og administrere slike system, må vi vidareutvikle den tradisjonelle sjukepleiarrolla.

Tradisjonelt blir pacemakerkontrollar utførte hjå ein hjartespesialist på sjukehuset. Ny teknologi gjer at ein del av kontrollane kan gjerast frå heimen. Telemonitorering (TM) har vist seg å vere trygt og ha fordelar for behandlinga (1-6). TM av pasientar med implantert hjartestartar er utbreidd, mens TM av pacemaker (PM) er mindre vanleg.

Sjukepleiaren administrerer TM-systema med ein hjartespesialist i bakhand og tek kontakt med pasienten når det oppstår hendingar som gir alarm. Ei slik hending kan til dømes vere feil på PM eller leidningar, eller påviste arytmiar. Pasienten tek kontakt med sjukehuset om han opplever behov for ekstra kontrollar eller har spørsmål om PM-behandlinga. 
Pacemaker (PM): Ei innoperert eining for behandling av bradyarytmiar. Indikasjonar omfattar symptomgjevande AV-blokk, sinusknutesjukdom og tilstandar som er prega av veksling mellom bradykardiar og takykardiar.

Telemonitorering (TM): Ein metode for fjernkontoll av ein pacemaker. Pasienten får med seg ein monitor frå sjukehuset til å plassere på nattbordet. Monitoren og pacemakeren kommuniserer trådlaust. Deretter blir det sendt ein rapport om teknisk tilstand og arytmibyrde til ein server som sjukehuspersonell har tilgang til.

Dei eldste pacemakerberarane: Denne gruppa er definert som menneske over 80 år med pacemaker i denne artikkelen.

\section{ENDRA SJUKEPLEIARROLLE}

Eldre som gruppe blir gløymde i utforming av retningslinjer for behandling av hjarte- og karsjukdommar, og prosentdelen eldre med aldersrelaterte kompleksitetar aukar. Det er behov for å omdefinere behandlingsstrategiar, måla og dei ønskte resultata for denne gruppa (7-9). TM kan vere ein nyttig strategi både for pasientar med få ressursar og dei som ynskjer å vere meir delaktige i si eiga behandling.

\section{«Nye roller krev også endringar i utdanningane og kompetansedefinisjonane.»}

For å greie å ta hand om pasientane og administrere slike system må vi tilpasse den tradisjonelle sjukepleiarrolla. Nye roller krev også endringar i utdanningane og kompetansedefinisjonane (10). Meld. St. 11 (2015-2016) skildrar at det er viktig å leggje til rette for vidareutdanningstilbod for legar og sjukepleiarar, og at det finst potensial for at fleire sjukepleiarar ved norske sjukehus kan få auka ansvar og kan utføre fleire oppgåver (11).

\section{PACEMAKERBEHANDLING}

I 2015 blei det implantert 3217 nye PM i Noreg. Dette er ein auke på 7,6 prosent frå 2014. Medianalderen for pasientar med PM er 78 år - dette vil altså seie at svært mange er eldre enn 78 år (12). Det vanlegaste er å få implantert ei PM-leidning gjennom venesystemet til høgre hjartekammer ved atrieflimmer. Ved AV-blokk eller sinusknutesjukdom legg ein vanlegvis to leidningar - éi til høgre forkammer og éi til høgre hjartekammer.

PM-generatoren er den delen av PM-en som inneheld batteri og dataprogram som styrer PM-funksjonen. Generatoren blir kopla til leidningane og lagd under huda, som oftast på venstre side av brystkassa under kragebeinet (13). Ein PM kan både registrere (sense) 
impulsane frå hjartet og generere impulsar (pace) dersom hjarteimpulsane er for langsame eller periodevis forsvinn. PM-en skal kontrollerast med faste intervall (14).

\section{BRUK AV TELEMONITORERING}

Omgrepa telemonitorering, heimemonitorering og fjernmonitorering blir brukte om kvarandre. Det vil seie at PM-en og ein monitor som pasienten har plassert på nattbordet, kommuniserer trådlaust. Det blir automatisk sendt ein rapport til ein database som sjukehuspersonell har tilgang til. Pasienten treng dermed ikkje gjere noko aktivt for å setje i gang sendinga. TM er ei klasse llaA-tilråding i europeiske retningslinjer (14).

TM er eit trygt alternativ til PM-kontrollar på sjukehuset, og dei gjer behovet for ordinære kontrollar mindre. (1-6; tabell 1). Forsking viser at PM-pasientar med TM har større overlevingsrate enn dei som ikkje har det (3). Det er då naturlegvis ein føresetnad at systemet blir brukt, at pasienten tidleg blir knytt til TM, og at sendingane blir raskt vurderte.

\section{«Forsking viser at pacemakerpasientar med telemonitorering har større overlevingsrate enn dei som ikkje har det.»}

Legen og sjukepleiaren vil som regel velje å inkludere pasienten i TM-systemet under opphaldet etter implantasjonen, og i alle fall helst i løpet av 14 dagar (2). Feil på PM og leidningar, eller arytmiar, løyser ut alarmar $(2,15)$. Dersom det oppstår alarmar som fører til oppmøteevaluering, er det sannsynleg at det blir sett i verk tiltak innanfor programmering eller medikamentell behandling som kan føre til betre resultat (3).

\section{FEIL OG ALARMAR}

Dei viktigaste funna hjå PM-pasientar er tidleg oppdaging av atrieflimmer. For tidleg utlading av batteriet, tidleg oppdaging av leidningsfeil, ventrikulære arytmiar og ugunstige innstillingar er også sentralt $(3,5)$.

Ei oppgåve for sjukepleiaren vil vere å filtrere alarmar og å stille dei inn i samarbeid med ein hjartespesialist. Alarmane kan og bør bli stilte inn individuelt $(2,3,15)$ slik at talet på alarmar som må handterast av hjartespesialisten, blir mogleg å handtere. Det krev at sjukepleiaren har god kunnskap om TM-system, bakgrunnen til pasienten, pacefunksjon og arytmiar.

Dersom ein organiserer tenesta slik at denne kunnskapen er på plass, har det vist seg at ein sparar tid og at arbeidet blir meir effektivt (15). Rutinekontrollar ved sjukehuset omfattar teknisk kontroll av PM og avlesing av batteristand, men ofte utan forandring $i$ programmering eller medisinering.

Desse parametrane kan ein ha god oversikt over via TM, og dermed kan ein spare pasienten, pårørande, helsevesenet og samfunnet for reise til sjukehuskontrollar (1-2).

\section{MEIR TILFREDSE PASIENTAR}

Pasientar som har tokammer-PM, kan i større grad dra nytte av telemonitorering fordi ein då 
kan finne og skilje ut atriearytmiar, til dømes atrieflimmer (1). Dette er eit poeng for antikoagulasjon og førebygging av tromboemboliske hendingar som hjerneslag. Det kan òg ha relevans for frekvenskontroll av permanent atrieflimmer.

Når det gjeld rytmekontroll, kan ein komme raskt i gang med medisin eller elektrokonvertering for at pasienten skal få normal sinusrytme. (15). Helserelatert livskvalitet viser seg å vere lik for dei med ordinære kontrollar og dei med TM, og livskvaliteten betrar seg over tid i begge gruppene etter implantasjonen (4).

TM har vist seg å gjere pasientane meir tilfredse enn tradisjonelle kontrollar (2). Svært mange av dei som får pacemaker, er eldre menneske, og helsepersonell må vere bevisste på korleis dei introduserer TM for denne gruppa.

\section{VERDIGHEIT OG DELTAKING}

Det er viktig å rette merksemd mot kva behov den eldre pasienten har for å behalde og uttrykkje verdigheit (16). Uttrykksformene kan vere det å klare seg sjølv og å meistre, å ha ansvarsroller og det å kunne uttrykkje at ein er «ordentleg». Nokre opplever at verdigheita ligg i korleis dei tek seg ut som menneske. Dei kan ynskje å gi «rett» inntrykk og vise «rette» haldningar.

\section{«Helsepersonell stiller ofte lite krav til deltaking frå den eldre pasienten i avgjerder som handlar om dei sjølve.»}

Dei kan oppfatte at dei bør møte helsepersonell med å vere høflege, positive, tolmodige, forståingsfulle og mindre forlangande. Tap av verdigheit kan oppstå dersom vi stiller krav til evner og kunnskap pasienten ikkje kan leve opp til (16). Helsepersonell stiller ofte lite krav til deltaking frå den eldre pasienten $\mathrm{i}$ avgjerder som handlar om dei sjølve.

Å vere deltakande blir av pasientane oppfatta som noko som krev god sjølvtillit. Årsakene til at det er slik, kan til dømes vere ulikskapar mellom generasjonar. Dei eldste kjem frå ei tid med meir samhald, audmjukskap og tolmod. Dei har levd gjennom fleire tider og kan dermed samanlikne verdiar og normer.

Det å framheve eigne individuelle behov kan av den gamle bli oppfatta som egoistisk og uhøfleg, men samtidig kan den gamle oppleve tap av verdigheit dersom han eller ho må gjere seg til for å gi «rett» inntrykk.

\section{DIDAKTISKE PRINSIPP}

I møte med den eldre pasienten med PM kan det oppstå utfordringar både når det gjeld kommunikasjon og læring. Didaktikk handlar om spørsmål kring undervisning og læring, og som rammeverk kan ein bruke den didaktiske relasjonsmodellen (17), som mellom anna har desse punkta:

Læreføresetnader: For å identifisere desse føresetnadene må vi kartleggje kva pasienten kan 
frå før og er interessert i, og om han har spesielle problem eller ressursar (17). Problem kan vere sansesvikt som redusert syn eller høyrsel, eller kognitiv svikt. Det krevst då meir tid og lågare tempo ved samtale (18-19).

Det er ikkje vist større risiko for komplikasjonar med innopererte einingar hjå eldre med kognitiv svikt $(7,20)$. TM av denne gruppa er viktig fordi dei kan ha problem med å få med seg oppmøtekontrollar og ta medikament (20). Det er viktig å sikre at pasientane har forståing for systemet, og vere merksame på dei det ikkje passar for.

Rammefaktorar: Forhold som avgrensar eller gjer læring mogleg. Døme kan vere tid, rom, lysforhold, forstyrrande lydar, utstyr, språket som blir brukt, og om pasienten kjenner seg trygg og orientert i omgivnadene. Til dømes må språket vi brukar, vere utan avansert fagterminologi, og ein må tilpasse kommunikasjon og informasjon individuelt (17-18).

Læringsaktivitetar: Det kan vere nyttig å demonstrere utstyret praktisk for så å la pasienten prøve å bruke det sjølv. Her er det gunstig å ha ei aktiviserande og konkretiserande tilnærming, og ein bør variere mellom munnleg og skriftleg informasjon. Informasjonen må individualiserast (17).

Det kan vere med på å motivere pasienten og byggje opp eit samarbeid mellom pasienten og sjukepleiaren. Dette kan i sin tur verke støttande for verdigheita til den eldre. Pasienten vil ofte ha behov for gjentakingar og konkrete bodskapar (21). Dette kan vi sikre ved telefonsamtale etter utskriving.

\section{ERFARINGAR FRÅ MALMÖ}

Ved sjukehuset i Malmö i Sverige er strategien å inkludere alle med tokammer-PM av eit visst merke i TM, og ein legg lite vekt på omsyn som geografi, demografi, alder og helsetilstand. Frå 2014 blei strategien «Implant and Forget» innført. Dette vil seie at PM-berarar med tokammeranlegg som oppfyller alle krav til automatiske kontrollar, ikkje har rutinekontrollar på sjukehuset, men blir følgde opp tett gjennom TM.

Mengda oppmøtekontrollar er kraftig redusert i forhold til tidlegare. Skal TM kunne erstatte oppmøtekontrollar, må ein ha komplett informasjon som inkluderer pacetersklar på alle leidningar og eit liknande oppsett som på merkespesifikke datamaskiner for pacemakerkontrollar (programmerar) (15).

Inklusjonsrutinane i Malmö omfattar informasjon i innkallingsbrev til elektive pasientar som skal ha PM, samtale ved sjukepleiar, utdeling av skriftleg informasjon og utstyr. Samtykkeskjema blir journalført, dei koplar pasienten opp mot TM mens dei er på sjukehuset og ringjer i etterkant når første sending kjem inn. Dette er viktige punkt i rutinane når ein tek inn pasientar i TM-oppfølginga (2).

Sjukepleiarane var utdanna PM-sjukepleiarar og administrerte TM-systema. Dei hadde ei sjølvstendig rolle innanfor diagnostikk og journalføring, og utførte PM-kontrollar poliklinisk og på pasientar som var innlagde. Pasientane kunne ta kontakt direkte med arytmiklinikken og ein PM-sjukepleiar dersom dei hadde spørsmål og behov for ekstra kontrollar. Slik sikra ein at pasientane var trygge ved at ein var tilgjengeleg, og det blei lagt til rette for deltaking og fremjing av verdigheit.

\section{FØRDE I SAERSTILLING}

Det blir implantert PM ved Førde sentralsjukehus, og vi har om lag 60 pasientar med TM. I 2015 blei det implantert 48 nye PM og bytta 25 generatorar ved Førde sentralsjukehus. Av dei som fekk ny PM, var 24 pasientar 80 år eller eldre (12). I Sogn og Fjordane blei tilbodet 
om TM til pasientar med PM etablert hausten 2014 som ei vidareføring av det allereie eksisterande kontrollopplegget for innopererte hjartestartarar (ICD) og hjartesvikt-PM (CRT).

TM av pasientar med PM er ikkje så vanleg andre stader i landet. Førde sentralsjukehus tilbyr TM til utvalde pasientar med PM og er dermed i ei særstilling i Noreg.

Vår demografi og geografi gjer det meir naturleg å samanlikne seg med dei nordlegaste fylka våre enn den folketette austlandsregionen. Det forventa folketalet i fylket i år 2030 er 117 400 personar, og heile folkeveksten fram mot 2030 er venta å komme i aldersgruppene over 60 år $(11,22)$ (figur 1).

\section{Figur 1: Talet på innbyggjarar i alderen 60 år og over}

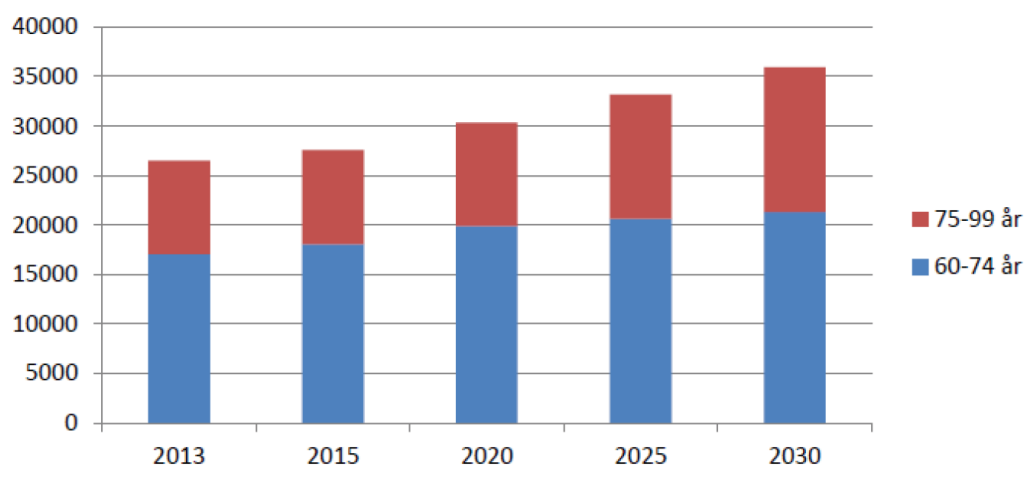

\section{FLEIRE FÅR TM}

Etter kvart har TM blitt eit tilbod til dei som kan ha stor praktisk fordel av det. Sjølv om det er flest pasientar med tokammer-PM som får TM, tilbyr vi det òg til dei som har einkammer-PM. Vi nærmar oss eit system for tilbod og oppfølging som det vi ser i Malmö. Telefonkontakt etter utskriving sikrar at pasienten får informasjon om at systemet fungerer, og pasienten får høve til å stille spørsmål.

Sjukepleiaren får samtidig høve til å gjenta viktig informasjon. Samtykkjeerklæring er ikkje vanleg i Noreg, og vi er ikkje komne i gang med informasjon i innkallingsbrev. Det er viktig å poengtere at systemet ikkje er ei kontinuerleg overvaking av eininga (15).

Vi ønskjer også at enkelte pasientar som har ein PM med dårleg batterikapasitet, får tilbod om TM i ein periode for å sleppe jamlege turar til sjukehuset i forkant av generatorskifte, samtidig som ein får utnytta kapasiteten i batteriet.

I Malmö garanterer dei at sendingar blir vurderte i løpet av ei veke. I Førde er vi som regel inne i systemet kvar yrkedag. Dette er det same på Haukeland universitetssjukehus, og dagleg gjennomsyn på yrkedagar er vanleg (5). Det vil også vere tett dialog mellom sjukepleiarar og kardiologar, slik at akutte tilfelle blir handterte raskt.

\section{GIR GOD INFORMASJON}

Sjukepleiaren ved poliklinikken kan vere med på å støtte verdigheita til pasienten ved å gi han ansvar og tillit til at han kan meistre det som blir kravd når det gjeld TM. Pasientar kan komme til å takke ja til tilbod vi gir dei, for å behalde verdigheita. Til dømes hadde ein 
pasient monitoren på nattbordet i eitt år utan å ha forstått meininga med dette, og samtidig uroa han seg over lys frå varsellampane.

Dette kan ha opphav i slett informasjonsarbeid, men det kan òg vere døme på at pasienten har takka ja utan å forstå kva det gjaldt, for å behalde verdigheit. Nokre pasientar ynskjer $\mathrm{TM}$, men vil at heimesjukepleia ordnar med det praktiske og er kontaktpersonar.

Sjukepleiaren ved poliklinikken kan tilby å diskutere TM med nær familie eller helsetenesta i kommunen. Samtidig er det viktig at pasienten alltid er inkludert i slike planar og har innverknad på dei avgjerdene som gjeld han eller henne sjølv.

Ein gong $\mathrm{i}$ året får pasienten ei skriftleg oppsummering i brevform. For å sikre tilgjenge får no pasientane utdelt telefonnummer til ein sjukepleiar ved poliklinikken og informasjon om at dei kan ta kontakt dersom dei har spørsmål som gjeld PM-behandlinga.

\section{ENDRA PASIENTROLLE}

Det er behov for å sjå på behandlingsstrategiar, mål og resultatvurdering for eldre med kardiovaskulære sjukdommar. Pasientrolla endrar seg, og TM kan vere eit tiltak for å få meir skreddarsydde forløp for dei eldste PM-berarane. Sjukepleiarrolla i poliklinikken endrar seg i takt med dette og stiller større krav til spesialisering. Sjukepleiestyrte hjartesviktpoliklinikkar er godt dokumentert (23).

\section{«Pasientrolla endrar seg, og telemonitorering kan vere eit tiltak for å få meir skreddarsydde forløp for dei eldste pacemakerberarane.»}

Forsking viser òg at spesialiserte sjukepleiarar gir gode tilbod til pasientar med atrieflimmer, til hjartepasientar som er under utgreiing (til dømes når sjukepleiarane fungerer som ultralydteknikarar), og til den stadig aukande gruppa av pasientar med pacemaker, ICD og CRT som skal følgjast opp (24-25).

\section{POTENSIAL FOR AUKA ANSVAR}

Meld. St. 11 (2015-2016) tek opp at det er viktig å tilby vidareutdanning ved norske sjukehus, og peiker på at det er potensial for at sjukepleiarar kan få auka ansvar og kan utføre fleire oppgåver (11). Pasientar med PM vil kunne dra nytte av at det blir utdanna fleire PM-sjukepleiarar, og ei organisering som i Malmö sikrar eit lågterskeltilbod til PM-pasientane.

Desse sjukepleiarane vil kunne utføre rutinekontrollar av teknisk stand og arytmibyrde i sjukehus, følgje opp pasienten via TM, ta hand om kvar enkelt pasient og sikre oppfølging frå kardiolog ved behov. Temaet for kongressen til Norsk Sykepleierforbund i 2016 var «Nye roller og innovasjon». Dette viser at temaet er viktig i tida, og at det er behov for fagleg spesialisering. Når det gjeld føringane om eit helsevesen for pasienten, tilgjenge og fleksibilitet, er ikkje dei nye sjukepleiarrollene eit hinder, men ein ressurs. 


\section{FORDELAR MED TM}

TM av pasientar med PM har ei rekkje fordelar - mellom anna tidleg oppdaging av tekniske problem og arytmiar. Når vi legg dette saman med dei praktiske fordelane systemet har for pasientane, pårørande og helsevesenet, ser vi at TM er eit nyttig alternativ til tradisjonell oppfølging av pasientar med PM.

Samtidig skal ein vere merksam på enkelte pasientgrupper, som dei eldste PM-berarane. Dei kan ha andre læreføresetnader og behov for andre rammefaktorar og læringsaktivitetar. Å fremje meistring kan verke støttande for verdigheita og deltakinga til pasienten.

Studiar viser lik livskvalitet hjå dei pasientane som har TM, og dei som går til ordinære kontrollar. Når det gjeld kor fornøgde brukarane er, tidsbruk på sjukehus og tidleg oppdaging av problem, kjem TM godt ut.

\section{REFERANSAR}

1. Mabo P, Victor F, Bazin P, Ahres S, Babuty D, Da Costa A, Binet D, Daubert J. A randomized trial of long-term remote monitoring of pacemaker recipients (The COMPAS trial). Eur Heart J. 2012 mai;33(9):1105-11.

2. Leahy RA, Davenport EE. Home monitoring for Cardiovascular Implantable Electronic Devices: Benefits to patients and to their follow-up clinic. Adv Crit Care. 2015 oktober-desember;26(4):343-55.

3. Varma N, Piccini JP, Snell J, Fisher A, Dalal N, Mittal S. The relationship between level of adherence to automatic wireless remote monitoring and survival in pacemaker and defibrillator patients. J Am Coll Cardiol. 2015 jun;65(24):2601-10.

4. Lopez-Villegas A, Catalan-Matamoros D, Robles-Musso E, Peiro S. Effectiveness of pacemaker tele-monitoring on quality of life, functional capacity, event detection and workload: The PONIENTE trial. Geriatr Gerontol Int. 2016 nov:16(11):1188-95.

5. Mairesse GH, Braunschweig F, Klersy K, Cowie MF, Leyva F. Implementation and reimbursement of remote monitoring for cardiac implantable electronic devices in Europe: a survey form the health economics committee of the European Heart Rhythm Association. Europace. 2015 mai;17(5):814-8.

6. Guedon-Moreau L, Mabo P, Kacet S. Current clinical evidence for remote patient management. Europace. 2013 jun;15 Suppl 1:i6-i10.

7. Rich MW, Chyun DA, Skolnick AH, Alexander KP, Forman DE, Kitzman D, Maurer MS, McClurken JB, Resnick BM, Shen WK, Tirschwell DL. Knowledge Gaps in Cardiovascular Care of the Older Adult Population. Circulation. 2016 mai;133(21):2103-22.

8. Forman DE. Bringing geriatric cardiology to the next level. Prog Cardiovasc Dis. 2014;57:125-26.

9. Forman DE, Rich MW, Alexander KP, Zieman S, Maurer MS, Najjar SS, Cleveland JC. Krumholz HM, Wenger NK. Cardiac care for older adults. Time for a new paradigm. J Am Coll Cardiol. 2011 mai;57(18):1801-10.

10. Dubner S, Auricchio A, Steinberg JS, Vardas P, Stone P, Brugada J, Piotrowicz R, Hayes DL, Kirchhof P, Breithardt G, Zareba W, Schuger C, Aktas MK, Chudzik M, Mittal S, Varma N. ISHNE/EHRA Expert Consensus on Remote Monitoring of Cardiovascular Implantable 
Electronic Devices (CIEDs). Europace. 2012 feb;14(2):278-93.

11. Meld. St. 11 (2015-2016). Nasjonal helse- og sykehusplan (2016-2019). Oslo: Helse- og omsorgsdepartementet; 2013.

12. Platou ES og Steen T. Norsk pacemaker- og ICD-statistikk for 2015. Hjerteforum. 2016;29(2):75-85.

13. Hayes DL. Permanent cardiac pacing: Overview of devices and indications. UpToDate Topic 941. Version 15.0. Tilgjengeleg frå:

https://www.uptodate.com/contents/permanent-cardiac-pacing-overview-of-devices-and-indications?search-permanent\%20cardiac\%20pacing:\% 200verview\%20of\%20devices\%20and\%20indications\&source-search_result\&selectedTitle=1 150\&usage_type-default\&display_rank=1 (lasta ned 01.05.2016).

14. Brignole M, Auricchio A, Baron-Esquivias G, Bordachar P, Boriani G, Breithardt O-A, Cleland J, Deharo J-C, Delgado V, Elliott PM, Gorenek B, Israel CW, Leclercq C, Linde C, Mont L, Padeletti L, Sutton R. og Vardas PE. 2013 ESC Guidelines on cardiac pacing and cardiac resynchronization therapy. Eur Heart J. 2013;34, 2281-2329.

15. Heidbuchel $\mathrm{H}$. Telemonitoring of implantable cardiac devices: hurdle towards personalised medicine. Heart. 2011;97(11):931-9.

16. Stikholmen T. «Ta vare på min verdighet». En kvalitativ studie om eldre pasienters behov for å opprettholde og uttrykke sin verdighet under sykehusopphold. Nordisk sygeplejeforskning. 2016;6(1):65-77.

17. Lyngsnes K, Rismark M. Didaktisk arbeid. 3. utg. Oslo: Gyldendal Akademisk; 2014.

18. Heap K. Samtalen i eldreomsorgen. Kommunikasjon-minner-kriser-sorg. 4. utg. Oslo: Kommuneforlaget; 2012.

19. Foss $\mathrm{C}$. Elders and patient participation revisited - a discourse analytic approach to older persons' reflections on patient participation. J Clin Nurs 2011 jul;20(13-14): 2014-22.

20. Jama A, Rubinstein A, Hodge D, Herges R, Asirvatham S, Cha Y, Powell B, Rea R. F, Friedman P. Cardiac device complications in the cognitively impaired. Pacing Clin Electrophysiol. 2013 september;36(9):1061-7.

21. Mach-Zagal R. \& Saugstad T. Sundhetspædagogik for praktikere. 3. utg. København: Munksgaard Danmark, 2009. s. 15-109.

22. Sogn og Fjordane fylkeskommune. Fylkesprognose Sogn og Fjordane 2014.

Tilgjengeleg frå: http://www.sfj.no/getfile.php/2957102.2344.bqsefpqved/fylkesprognose\%25202014_.pdf (Lasta ned 01.04.2015)

23. Fålun N, Instenes I, Norekvål TM. Hjertesvikt krever spesialkompetanse. Tidsskriftet Sykepleien. 2013;13:68-70. Tilgjengeleg frå: https://sykepleien.no/forskning/2013/11/hjertesvikt-krever-spesialkompetanse (lasta ned 22.12.2017).

24. Husby MI, Antonsen A, Nilsen HO, Ryggvik T, Gjeilo K.H. Bedre tilbud til hjertesyke. Tidsskriftet Sykepleien. 2014;14:66-9. Tilgjengeleg frå: https://sykepleien.no/forskning/2014/12/bedre-tilbud-til-hjertesyke (lasta ned 22.12.2017). 
25. Jørgensen $M$, Gundersen GH. Målrettet ultralyd til hjertepasienter. Tidsskriftet Sykepleien 2017;4:58-61. Tilgjengeleg frå: https://sykepleien.no/forskning/2017/03/malrettet-ultralyd-til-hjertepasienter (lasta ned 22.12.2017).

26. Wikipedia. Sogn og Fjordane [internett]. Tilgjengeleg frå: https://no.wikipedia.org/wiki/Sogn_og_Fjordane (lasta ned 01.04.2016).

27. Askheim S. Sogn og Fjordane. Oslo: Store norske leksikon. Tilgjengeleg frå: https://snl.no/Sogn_og_Fjordane (lasta ned 01.04.2016).

28. NAF ruteplanlegger. Tilgjengeleg frå: https://www.naf.no/tjenester/ruteplanlegger (lasta ned 19.12.2017). 